\title{
Predictors of nurse's happiness: a systematic review
}

\author{
Judie Arulappana,*, Suthan Pandarakutty ${ }^{\mathrm{b}}$, Blessy Prabha Valsaraj ${ }^{\mathrm{c}}$ \\ aDepartment of Maternal and Child Health, College of Nursing, Sultan Qaboos University, Al Khoud, Muscat 66, Sultanate of Oman \\ ${ }^{b}$ Lecturer of Nursing, University of Buraimi, Al Buraimi, Buraimi 890, Sultanate of Oman \\ 'Department of Community and Mental Health, College of Nursing, Sultan Qaboos University, Al Khoud, Muscat 66, Sultanate of Oman
}

Received: 9 February 2021; Accepted: 28 April 2021; Published: 20 December 2021

\begin{abstract}
Objective: An acute shortage of nurses exists all over the world. Part of this shortage appears to be due to nurses' low job satisfaction, low retention, and high turnover. Happiness at work is identified as a contributing factor that determines the shortage of nurses across the world. This paper critically appraised the existing scientific articles that assessed the individual and organizational predictors of happiness among nurses.

Methods: The systematic review was conducted from August 2010 to August 2020 using Preferred Reporting Items for Systematic Reviews and Meta-Analyses (PRISMA) guidelines. Scientific articles were searched in the electronic databases (Scopus, Medline, CINAHL, PsychINFO, and Pubmed Central) on the predictors of happiness among nurses.

Results: A total of 13 articles were selected following the literature search and a thematic analysis was done. This review provides updated evidence on the predictors of nurses' happiness. Job-related predictors were identified as organizational predictors; and personal, psychological, family, social, and spiritual predictors were reported to be the individual predictors.

Conclusions: As both individual and organizational predictors determine the happiness of nurses, the authors recommend the need for future interventional studies to increase the nurses' happiness, their mental health, and health-related quality of life.
\end{abstract}

Keywords: predictors $\bullet$ factors $\bullet$ happiness $\bullet$ joy $\bullet$ well-being $\bullet$ life satisfaction $\bullet$ nurses $\bullet$ registered nurses

(C) Shanxi Medical Periodical Press.

\section{Introduction}

Happiness is a fundamental human feeling that is essential for the well-being and development of any individual, society, and an organization. Happiness is "an emotional or affective state that is characterized by feelings of enjoyment and satisfaction, which is often equated with morale, contentment, well-being, life satisfaction, successful aging, quality of life, and the good life."1 Happiness brings positive self-concept, physical, psychological, and social well-being, brings better hope for the future, and positive attitude toward oneself and others, improves relationship with the family and society, motivates to serve others, provides better decision-making ability, and brings more creativity. ${ }^{2,3}$ Happiness is one of the critical factors essential for achieving a satisfactory performance and increased output, leading to economic, cultural, social, and political development. ${ }^{4}$ Several countries including France, Canada, and the United Kingdom have recently used national happiness index as an indicator of national success. $^{5}$

How to cite this article: Arulappan J, Pandarakutty S, Valsaraj P. Predictors of nurse's happiness: a systematic review. Front Nurs. 2021;4:313-326. 
Happiness is directly linked to the work environment because people are spending most of their time in their job, which is greatly contributing to their happiness and well-being. ${ }^{6}$ Happier people are more satisfied in their life, experience less burnout at workplace, absent less, are reluctant to leave their jobs, have stronger interpersonal and communication skills, and are dedicated to their organization. ${ }^{7,8}$ When people are happy in their workplace, not only do they have a sense of well-being, optimism, and hope for the future but it also benefits the organization. Satisfied workers are innovative and productive and can make positive choices and strengthen their relationships with others. ${ }^{9}$ Nursing profession has been listed in the top 40 high-stress jobs. ${ }^{10}$ As nurses are involved in caring, they have to be happy in order to be more productive to deliver high-quality nursing care. ${ }^{11,12}$ It has been reported that $7.4 \%$ of the nurses are absent each week due to stress-induced deterioration or impairment, which is $80 \%$ higher than that of other occupational classes. ${ }^{13}$ It is also highlighted that only one in seven nurses is happy when they are working in hospitals, ${ }^{14}$ and one out of every five nurses leave their job in the first 5 years due to work stress. ${ }^{15}$

Nurses are unhappy due to the constant exposure to patient's pain and sufferings, the uncertainty of patient's conditions, caring for death and dying patients, lack of resources in the workplace, inadequate peer and organizational support, lack of understanding and communication with their supervisors and physicians, lack of staff, and poor teamwork. ${ }^{16-18}$ These factors add more physical and mental strain on the nurses and lead to the development of depression, inability to perform job duties, reduction in the standard of care, increased conflicts in the work environment, dissatisfaction in the job, and even chances of leaving the profession. ${ }^{19,20}$ Nurses are also suffering from a greater level of physical, mental, and family disruptions including changes in daily routine activities such as sleep, anger, agitation, fatigue, misery, displeasure, desperation, feeling of inadequacy, depression, and changes in role function. ${ }^{21}$ Nurses experience negative impacts of high workload including delayed prescription of care, increased drug problems, and inadequate patient education. ${ }^{22}$ Nurses also reported having heavy workload, insufficient staff, aging nurse workforce, policies and management systems not helping nurses, inadequate pay, lack of resources and supplies, limited job opportunities, limited educational opportunities, and poor working conditions. ${ }^{23,24}$ Therefore, happiness of nurses is a critical factor influencing employee turnover and is related to vocational calling, work independence, and professional nursing values. ${ }^{25}$

Healthy Nurse's Year, 2017, emphasized the need for empowering nurses to achieve happiness in both their personal and professional lives. ${ }^{26}$ Nurses should be helped in discovering the things that give them energy and make their lives enjoyable and build highquality and comfortable work atmosphere. ${ }^{27}$ As happy employees maintain a good relationship with everyone in the organization, make the right decisions, are more creative, and are beneficial, ${ }^{10}$ understanding the factors that promote their happiness is the key in planning and delivering appropriate strategies to make them happy and to develop a sense of well-being. Understanding the individual and organizational predictors of nurse's happiness will not only provide the baseline data but also serve as evidence to the organizations to plan and design strategies to make the nurses happier, retain them, and make them more productive at their workplace in order to deliver high-quality nursing care. This will bring innovations and research contributions to the nursing profession, and the entire community can benefit from it.

Though understanding both the individual and organizational predictors of nurse's happiness is very essential to recognize the reasons for their low job satisfaction, low retention, and high turnover, a limited number of studies have been conducted in this area. Most of the studies have been conducted on the stress, job satisfaction, burnout, and mental health aspects of nurses. However, to the best of our knowledge, no systematic review has been carried out on the predictors of nurses' happiness. Therefore, this review will systematically bring out all the possible predictors of nurses' happiness in order to identify the possible strategies to enhance the nurses' happiness. Thus, the objective of this review was to investigate the potential individual and organizational predictors of nurses' happiness, specifically, to address the research question "What are the factors that may influence the happiness among nurses working at various hospitals?"

\section{Methods}

A systematic review was conducted according to the Preferred Reporting Items for Systematic Reviews and Meta-Analyses (PRISMA) recommendations. ${ }^{27}$ This systematic review was used to appraise and synthesize articles that examined the predictors of nurses' happiness among the nurses working in hospitals.

\subsection{Search strategies}

Electronic databases such as Scopus, Medline, CINAHL, PsychINFO, and Pubmed Central were used to identify relevant articles. The keywords included were "predictors," or "factors," "happiness," or "joy," or "well-being," or "life satisfaction," "nurse," or "registered nurse," and "individual or organizational." 


\subsection{Inclusion and exclusion criteria}

The research studies were included based on the following criteria: (1) the study measured the predictors or factors influencing nurse's happiness, (2) the participants were qualified registered nurses (male or female of any age) who were working in the hospitals or clinics, (3) full-texted and peer-reviewed articles that were published in English language, and (4) published between August 2010 and August 2020. Articles that did not assess the predictors of nurses' happiness or that assessed general aspects of nurses' happiness and the articles that assessed nurses' stress, burnout, and job satisfaction were excluded from this review. Studies published before 2010, studies that did not have study protocols, studies that had no or insufficient outcomes, studies in a language other than English, unpublished studies, pilot studies, thesis, and dissertations were not included in the current systematic review.

\subsection{Search outcomes}

The systematic search yielded 1513 articles. After removing duplicates, reading titles, and abstracts, it was found that 875 articles were not relevant to the objective of the review, leaving 52 items for full-text review. After the review of 52 full-texted articles, only 13 articles that met all the inclusion criteria were included in the systematic review ${ }^{28-40}$ (Figure 1).

\subsection{Appraisal of methodological quality}

The methodological quality of each descriptive studies (cross-sectional, correlational, and descriptive-comparative studies) was assessed using the adapted versions of the Newcastle-Ottawa Quality Assessment Scale. ${ }^{41}$ For each cross-sectional, correlational, and descriptive-comparative analysis, the maximum achievable score was 8 . We included four sample selection items, one comparability item, and two outcome measurement items. A high score in the category was awarded while meeting all requirements in the category. Studies that met $<50 \%$ of the requirements were considered to have a low score, except for the comparability criterion of a cross-sectional sample. The methodological quality of each quasi-experimental and qualitative studies was evaluated by the Mixed Methods Appraisal Tool (MMAT). ${ }^{42}$ The quasi-experimental studies were assessed on the basis of the existence of selection bias, the suitability of the measurements, the presence of the control group, and the completeness of the outcome results. The quality scores of all the included quasiexperimental and qualitative studies were good to excellent, ranging from $75 \%$ to $100 \%$.

\subsection{Data extraction and synthesis}

The selection process began by reading the titles and summaries of each article. All the titles and abstracts of the retrieved papers were screened after the elimination of duplicates. For eligibility, full-text articles of potentially relevant studies were analyzed, and two authors independently performed data extraction. The authors then collected relevant data from the articles and consolidated it into an article review matrix (Table 1). Column variables in the table were authors, country, year, purpose, research approach, relevant findings, possible predictors of happiness, and quality assessment scores.

\subsection{Research methods}

\subsubsection{Research design}

Six of the included studies used cross-sectional research designs, ${ }^{29,30,32,34,36,39}$ two adopted descriptive-comparative designs, ${ }^{31,40}$ two used correlational designs, ${ }^{28,35}$ two had quasi-experimental designs,,$^{33,37}$ and one had qualitative research design. ${ }^{38}$

\subsubsection{Study settings and sample size}

Five of the studies originated from Iran, ${ }^{33,34,36,37}$ and the remaining studies were conducted in Saudi Arabia, ${ }^{32}$ Turkey, ${ }^{28}$ Peru, ${ }^{29}$ South Korea, ${ }^{30}$ Poland, ${ }^{31}$ China,${ }^{35}$ the United States of America, ${ }^{38}$ Iceland, ${ }^{39}$ and Pakistan. ${ }^{40}$ All the studies were conducted in hospitals and included registered staff nurses as the samples. The sample size varied from 32 to 620 and included male and female hospital nurses (Table 1).

\subsubsection{Measures of happiness}

Four of the studies used the Oxford Happiness Questionnaire (OHQ), ${ }^{28,30,33,36}$ two studies used The Happiness Scale by Fordyce (1988), ${ }^{34,38}$ one qualitative research used semi-structured interview, ${ }^{39}$ and the remaining studies used the following scales: List of Personal Values (LPV) scale by Juczyński (2001), ${ }^{31}$ Scale of Happiness by Alarcón (2006), ${ }^{29}$ Happiness subscale by Warr et al. (1979), ${ }^{32}$ Life Satisfaction Index A (LSIA) by Neugarten (1961), ${ }^{37}$ Life Satisfaction Ladder Scale by Robinson and Strauser $(2002)^{40}$ and the Multiple Happiness Questionnaire (MHQ). ${ }^{35}$

\section{Results}

In this systematic review, 13 studies ${ }^{28-40}$ were chosen (Table 1) and a thematic analysis was done. The authors categorized various predictors from 13 studies $^{28-40}$ into 


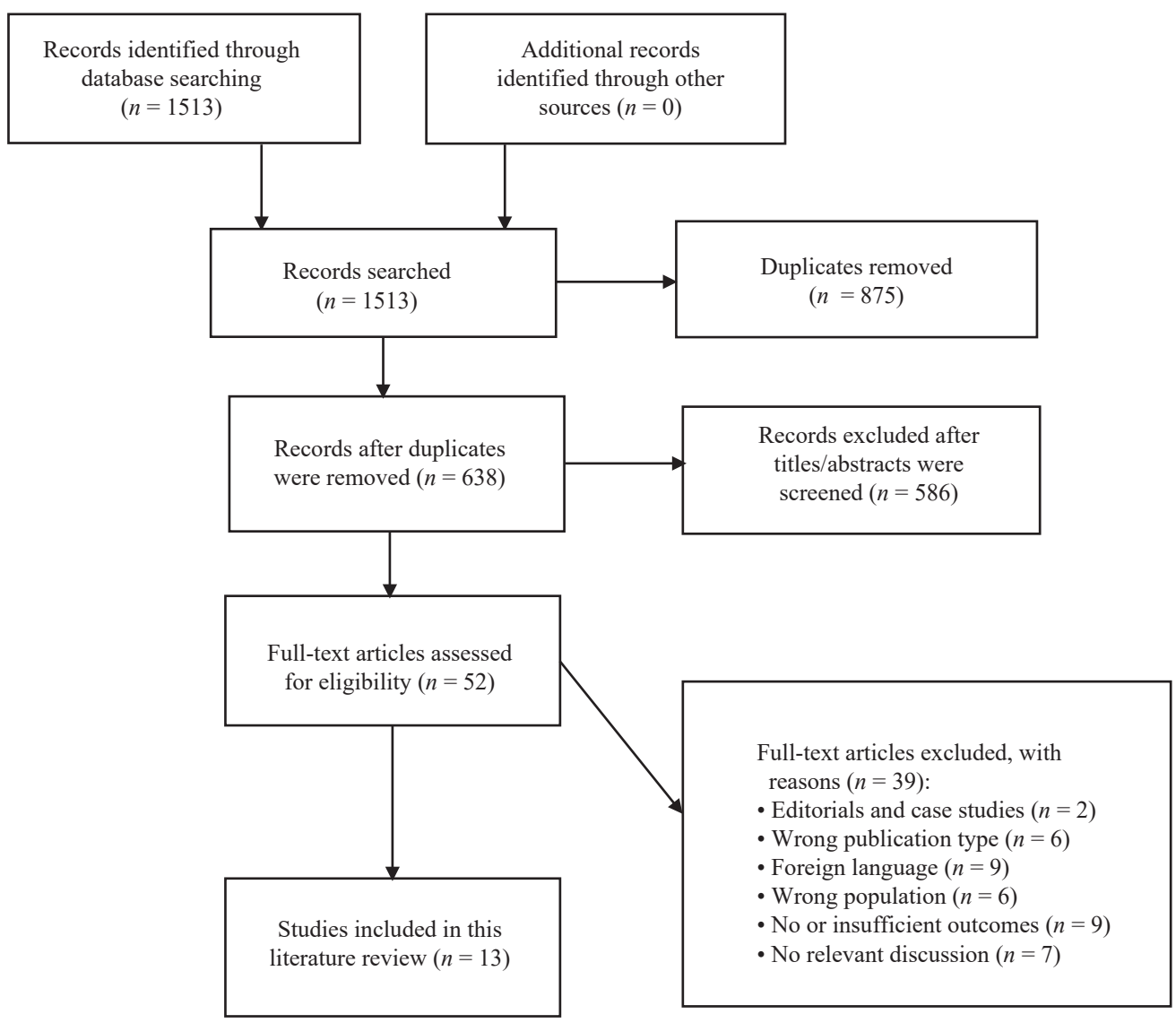

Figure 1. Literature search flowchart.

two main domains: (1) Organizational or job-related predictors and (2) personal predictors including psychological, family, social, and spiritual factors.

\subsection{Organizational or job-related predictors}

Eight of the included studies stated that the nurses' happiness primarily depends on the work-related factors. ${ }^{29-32,36-38,40}$ Studies have shown that nurses' job position, working style, and working units significantly affected the nurses' happiness and their quality of life. ${ }^{28,37}$ Autonomy in carrying out job duties and other job-related tasks significantly contributed to nurses' happiness. ${ }^{29}$ Four studies reported the working unit, satisfaction with salary, the time duration of working in the current ward, job shift, satisfaction with physician's conduct and performance, and having a second job offer as the significant predictors of nurses' happiness. . $^{32,33,36,37}$ Awareness of job duties and types of hospitals the nurses work were considered as job-related predictors for nurses' happiness. ${ }^{31}$ In addition, professional pride, professional titles, and preferred job duties were found to be the predictors for nurses' happiness. ${ }^{30,35,38,39}$

\subsection{Personal predictors including psychological, family, social, and spiritual predictors}

Eight of the included studies discussed the personal factors that affected the nurses' happiness. ${ }^{28-30,32-37}$ Some of the personal factors of happiness identified included a positive sense of life, personal fulfillment, and joy of living. ${ }^{28}$ Individual subjective estimation of nurses' health status is found to be a strong predictor of their happiness. Two studies added quality of life as a significant predictor for nurses' happiness. ${ }^{30,32}$ Age, gender, marital status, and educational level of the nurses also were considered as the predictors for their happiness. ${ }^{32,36}$ It's interesting to note journaling as a novel predictor of nurses' happiness. ${ }^{37}$ Furthermore, life skills education including effective communication, selfawareness, anger management, and coping with stress were considered as the other predictors for nurses' happiness. $^{33}$

Besides the factors reported above, satisfaction with mental health and positive emotions were identified as strongest predictors for nurses' happiness. ${ }^{32,34,37}$ 


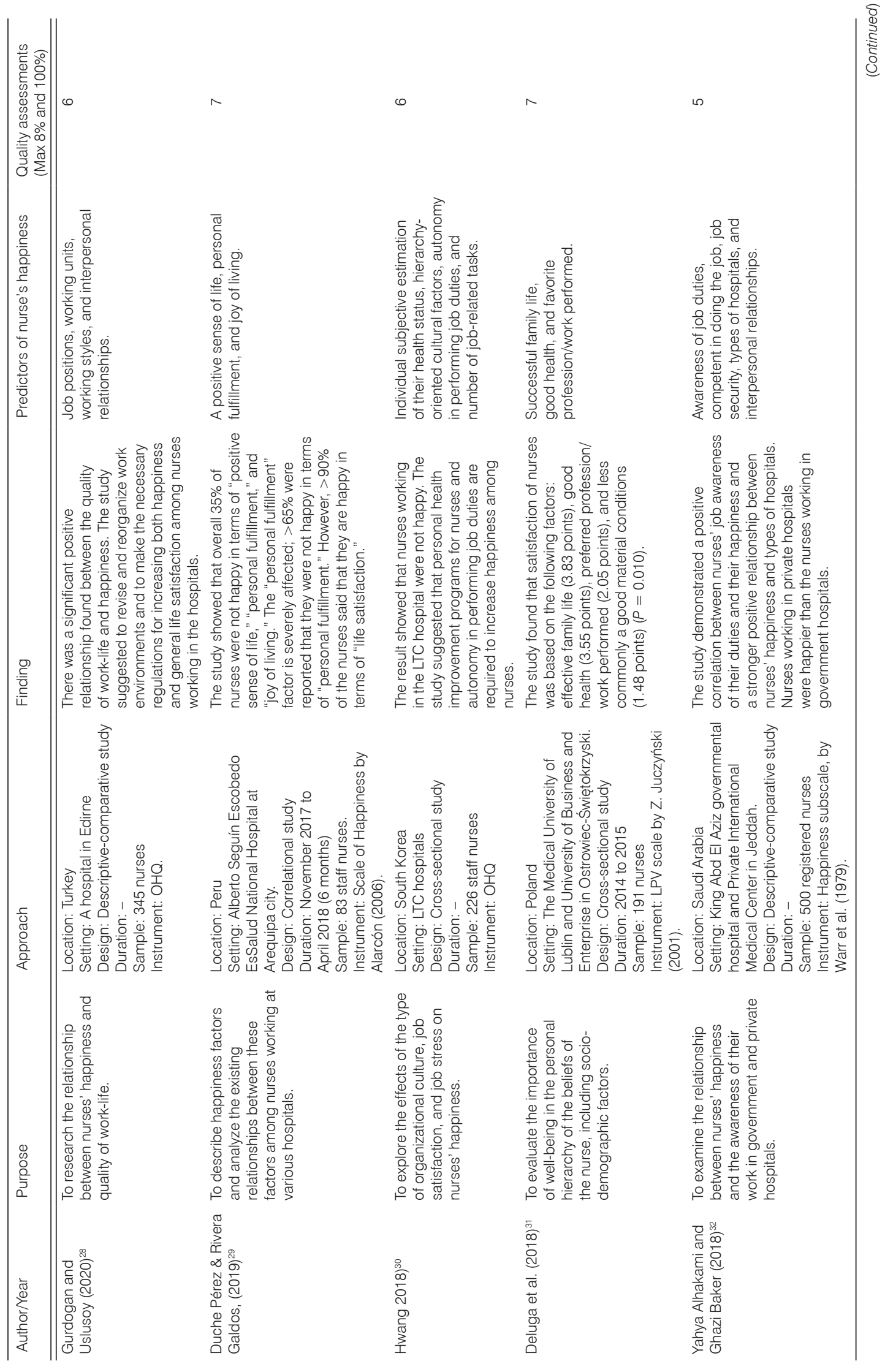




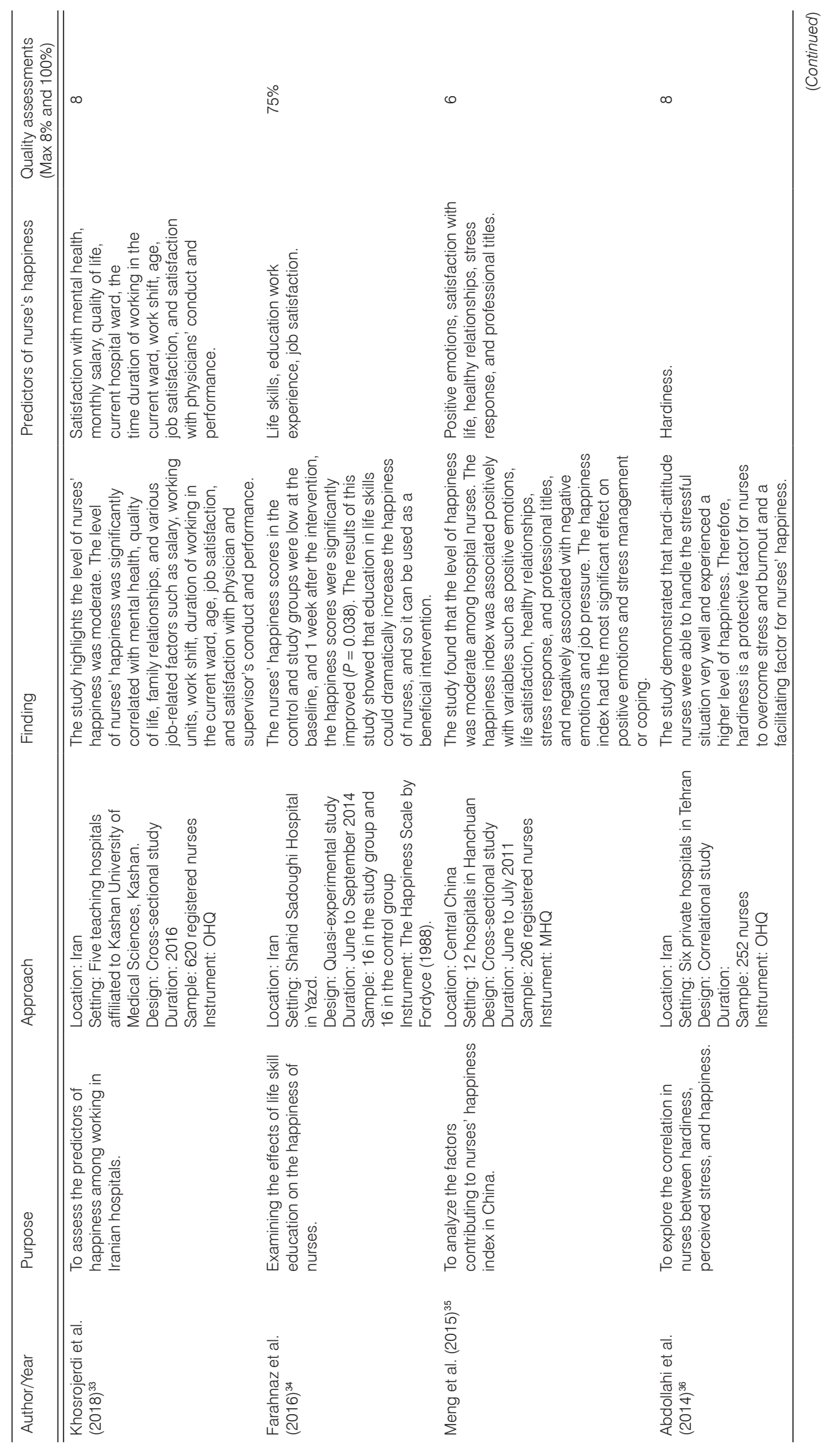




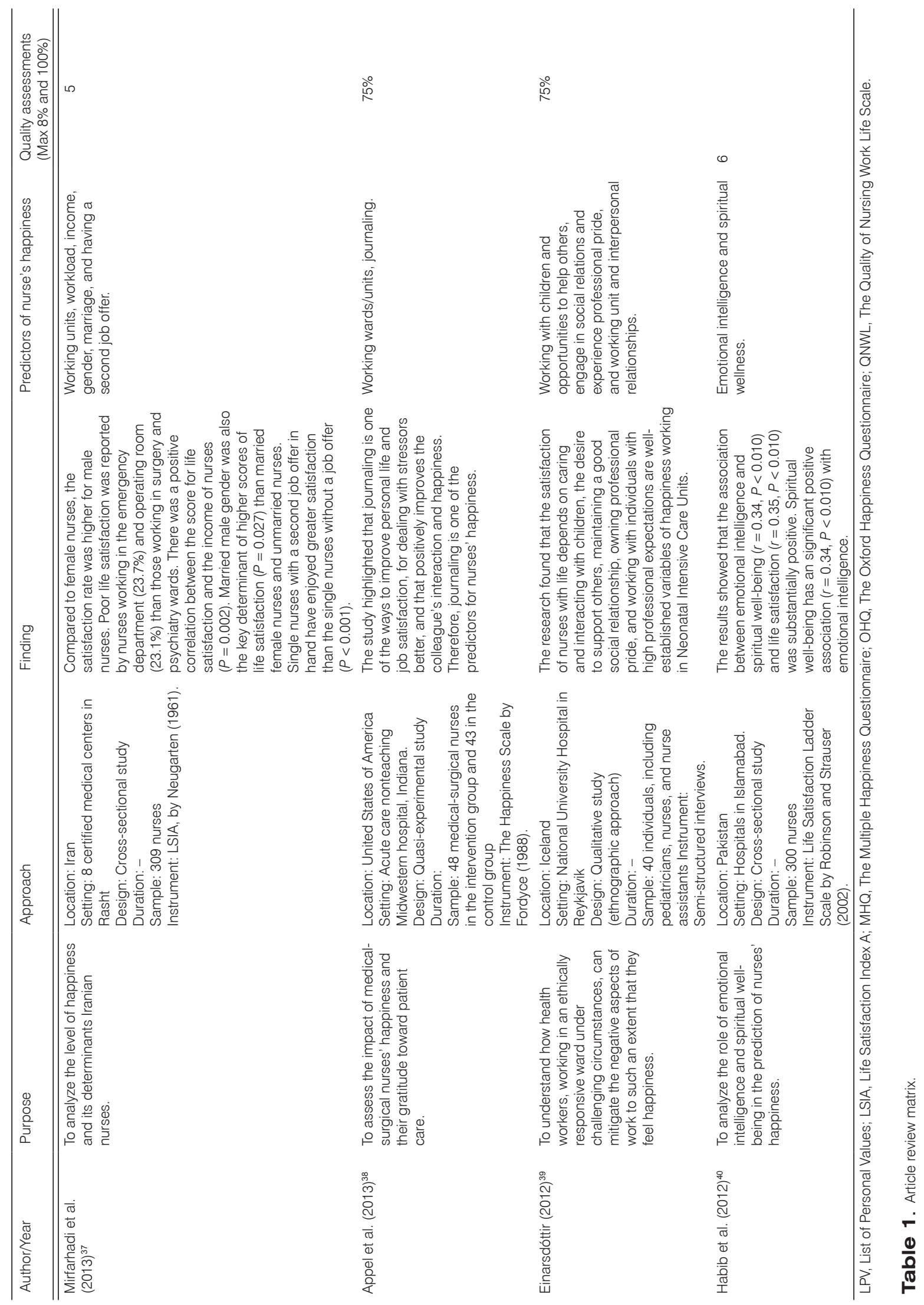


Emotional intelligence and spiritual wellness also are reported as essential predictors for nurses' happiness. Having a healthy family, good peer relationships, and social well-being are essential for nurses' happiness. ${ }^{29,30,34-36,38}$ Nurses engaging in a family, social, and peer relationships are considered to be happy. ${ }^{34,38}$ Additionally, working with children and opportunities to help others are the essential factors for happiness. ${ }^{38}$ Finally, hardiness is one of the most significant predictors for nurses' happiness. ${ }^{36}$

\section{Discussion}

This systematic review was aimed at identifying both the individual and organizational predictors of nurses' happiness. To our knowledge, this is the first systematic review that has explored all the predictors of nurses' happiness from various studies across the world. Studies included in this analysis showed that the overall level of nurses' happiness was moderate. ${ }^{32,34-36}$ Similar findings have been reported in a few more studies. ${ }^{43-45}$ However, two studies reported contrary findings: in one study, the level of nurses' happiness was a little above the average,${ }^{46}$ whereas in another study, the nurses' happiness was below the average level. ${ }^{47}$ These differences could be due to various factors in the settings where these studies have been conducted. However, further studies are recommended to identify the reasons for higher and lower levels of happiness among nurses.

In our analysis, organizational or workplace-related factors were found to be the predictors of nurses' happiness. These include job satisfaction, types of hospitals, working units, job positions, working styles, time duration of working in the current ward, work shift, autonomy in performing job duties, number of job-related tasks, awareness of job duties, job satisfaction, satisfaction with salary, satisfaction with physician's conduct and performance, work experience, job competencies, having second job offer, and experience as professional pride. ${ }^{28,29-32,36-38}$ Similar findings are reported in another two studies. ${ }^{47,48}$ In a recent concept analysis, it is shown that the work environment including personal, work-related, and workplace-related factors are the critical elements that promote nurses' happiness. ${ }^{10}$ Lin et al. (2011) ${ }^{23}$ also confirmed that heavy workloads, inadequate staff, aging nurse workforce, policies, and management systems not helping nurses, inadequate pay, lack of resources and supplies, limited job opportunities, limited educational opportunities, and poor working conditions as the work place-related factors that predict the nurses' happiness. There is a positive association between the quality of work-life and the nurses' happiness..$^{49}$ Nurses who are stressed more in their job experience a lower level of happiness due to a lower level of energy and difficulty in maintaining a balance between the professional and personal lives..$^{50}$ Creating conducive working environment is very much important in enhancing the happiness of nurses.

We identified working unit and workload as the significant predictors of nurses' happiness. ${ }^{28,36-38}$ Nurses working in the surgical unit found to have low level of happiness and reduced quality of life..$^{51}$ In contrast, another study stated that the nurses working in the surgical units reported to be happier than those working in the medical wards. ${ }^{52}$ Further data is needed to confirm these contradictory findings of the study. Several studies have shown that the nurses working in ICU and Critical Care Units (CCU) were not happy and reported to have a high level of job stress, anxiety, depression, burnout, and lower level of happiness than the nurses working in other units. ${ }^{48,53-55}$ In another study conducted in Iran with 21,767 ICU nurses, the nurses working in ICU were found to be less happy. ${ }^{56}$ This data is alarming and indicating the need to identify the reasons for low level of happiness among nurses working in CCU. We, therefore, recommend additional data to confirm these results and develop strategies to improve the satisfaction and happiness of nurses working in ICU and CCU.

Al Sinawi et al. (2016) $)^{57}$ stated that the nurses working in medical, surgical and obstetrics/gynecology wards were not happy due to excessive stress and burnout. Ghanbary and Bqayy (2010) ${ }^{58}$ mentioned that the nurses working in the cancer care units were not happy and exposed to a higher level of stress and occupational burnout. Besides, studies also have reported that work shift and workload are affecting the quality of sleep, family relationships, and quality of life of nurses. ${ }^{59}$ On the contrary, two studies have shown that there was no correlation between the nurses' happiness and the working unit or ward. ${ }^{44,48}$ Therefore, the reasons for the contradictory findings need to be tested in future studies. The nurses who were aware of their job duties, who were competent in their job, were having a feeling of job security, and had more work experience were found to be happier. ${ }^{4,6}$ Toode et al. $(2014)^{60}$ and Warr $(2013)^{61}$ also reported similar findings. Blumberga and Olava $(2016)^{62}$ confirmed that the nurses with job security and more work experience show better coping with workrelated stress, which promoted their independence and self-confidence and resulted in overall happiness. Therefore, nurses should be well oriented to their duties and should be trained well to develop their clinical competencies. This, in turn, will improve their job satisfaction and happiness.

Supportive work environment, professional autonomy, and professional titles are identified as the predictors of nurses' happiness ${ }^{30,34,38}$ Another two studies also confirmed that happiness at work was positively 
linked to a healthy work environment. If the organization has a fair rewarding system, has good collaboration with the staff, is committed and appreciates one's hard work, the employees would be happy. However, if the organization does not have a fair system of functioning, it would negatively cause stress and burnout, frequent absenteeism in work, job dissatisfaction, and emotional

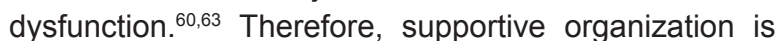
essential to improve the happiness of the nurses. Laschinger et al. $(2014)^{64}$ stated that if a nurse leader creates a supportive work environment, it will lead to improved work productivity and enhanced general well-being of nurses. Mousavi et al. (2019) ${ }^{65}$ reported that there was a positive, significant association between professional autonomy and nurses' happiness. Furthermore, professional titles and clear job descriptions could increase the happiness of nurses. ${ }^{66}$ As professional autonomy is considered to be an important predictor of happiness of nurses, the authors recommend organizations to consider strategies to enhance the autonomy of nurses.

Likewise, monthly salary is reported to be a significant predictor of nurses' happiness. ${ }^{32,36}$ Consistent findings have been reported in another two studies. ${ }^{67,68}$ Nurses salary is found to be increasing the level of their happiness and directly influencing the quality of health care delivery and productivity of work in their organization. ${ }^{69}$ Low salary exacerbates depression and family conflicts, and it results in social isolation, ill health, and divorce. ${ }^{70}$ We recommend the healthcare organizations to consider increasing the salary of nurses to make them happy and satisfied, which will enhance their work productivity. Maintaining harmonious and supportive interpersonal relationships among co-workers helps to relieve stress and maintain a positive emotion and happiness among nurses. ${ }^{28,31,32,38}$ Also, happiness depends on the mutual appreciation between colleagues, gratitude, love, and support that help to reduce work-related stress and maintain a harmonious relationship with others. ${ }^{71}$ Cooperative interpersonal relationships with doctors, supervisors, and other nurses also significantly contribute to nurses' happiness. ${ }^{72}$ This makes it very evident that harmonious interpersonal relationship is indispensable to enhance happiness among nurses.

The second major theme identified in our analysis is the personal predictors. Nurses' age, gender, marital status, education, quality of life, positive sense of life, personal fulfillment, the joy of living, individual subjective estimation of their health status, life skills education, journaling, and hardiness were identified as personal predictors of nurses happiness. ${ }^{28-30,32-37}$ Three of the studies indicated that the age, gender, education, and marital status were directly associated with the nurses' happiness. ${ }^{32,36,38}$ In another two studies, age, gender, education, and marital status were significantly correlated with the nurses' happiness. ${ }^{73,74}$ Marital well-being is an important factor for job satisfaction and happiness of nurses. ${ }^{75}$ On the contrary, two studies showed that the age, gender, education, marital status, and work experience were not related to nurses' happiness. ${ }^{48,76}$ These contradictory findings need to be investigated further to find the reason for conflicting findings.

Quality of life was considered to be another predictor of nurses' happiness. ${ }^{28,32,34}$ Similar results are found in one more study. ${ }^{59}$ The quality-of-life-determining factors identified in the aforementioned studies were adequate nutrition, a non-hazardous environment, and a long and healthy life. ${ }^{77}$ Sleep is one of the primary components of quality of life. Nursing staff with good sleep were happier compared to those with poor sleep. Majority of the nursing staff were found to be unhappy due to poor sleep. ${ }^{78}$ This clearly shows how sleep is important in predicting nurses' happiness. Therefore, their sleeping pattern has to be improve to be happy and healthy.

Life satisfaction and personal fulfillment are found to be the personal predictors of nurses' happiness. ${ }^{28,35,36}$ Liu et al. (2018) ${ }^{79}$ also reported that the nurses who were happy in their life achieved higher levels of life satisfaction. In addition, happiness is strongly associated with personal fulfillment. Life satisfaction also depends on the nurses' personal values to life, personality, passion, empathy toward patient care, and dedication to work, which further contribute to their happiness. ${ }^{80}$ Strategies including life skills education, such as effective communication, self-awareness, anger management, and coping with stress, significantly improve the nurses' happiness. ${ }^{33,81,82}$ Hardi-attitude and journaling help the nurses to cope up with stressful situation, improve personal life, enhance job satisfaction, and improve the colleague's interaction and happiness. ${ }^{35,37,83}$ In order to have happiness and life satisfaction, the nurses need to have positive values to life and should develop passion toward the nursing profession.

In addition to the personal predictors mentioned above, psychological, family, social, and spiritual predictors including the successful family life, satisfaction with mental health, positive emotion, emotional intelligence, friendly relationships, working with children and opportunities to help others, engaging in social relations, hierarchy-oriented cultural factors, and spiritual wellness were found predicting the happiness of nurses. $29,30,32,34,38,39$ Another two studies also demonstrated that mental health was directly related to nurses' happiness and life satisfaction. ${ }^{67,84}$ Australian nurses were not happy due to depression and job stress. ${ }^{85}$ In the United Kingdom, mental health was the main factor than the workplace factor that correlates with the nurses' happiness. ${ }^{86}$ Nurse's negative emotions were significantly associated 
with nurses' happiness. Negative emotions identified were excessive job stress, misunderstanding with doctors and co-workers, nurses' educational level, and patients' mental status. ${ }^{87}$ Nurses who experienced lower emotional stress and higher personal accomplishment experienced greater life satisfaction and happiness. ${ }^{88}$ This data very clearly demarcates that the mental health of nurses should be taken care off in order to make them happy and have life satisfaction.

Besides the abovementioned factors, happiness also depends on a successful family and marital relationship. ${ }^{30,36}$ Lewicka et al. (2013) ${ }^{89}$ reported that family relationship, good health, physical and mental fitness, love and friendship, knowledge and wisdom, intelligence and mental acuity, joy and satisfaction as the contributing factors for nurses' happiness. It is reported that the married people are happier than those who are unmarried, widowed, or separated. ${ }^{90}$ Moreover, another study reported that happiness is directly related to family relationships and it improves emotional health of nurses. ${ }^{88}$ Thus, having a happy and harmonious family life is essential for the nurses to be happy. Nurses' happiness and satisfaction with life is related to caring and engaging with children, the opportunity to help others, maintaining a good social relationship, having professional pride, and working with people having high professional ambitions. ${ }^{38,91}$ Family and social support are extremely important for nurses to maintain emotional balance and are moderately or strongly correlated with happiness and life satisfaction. ${ }^{67}$ Therefore, nurses should be provided with opportunities to maintain good social relationship and should be treated with respect in the society as they maintain high professional values.

Spiritual health was directly related to the nurses' happiness. ${ }^{39}$ Happiness is greatly linked to all dimensions of spiritual health and nurses' happiness. ${ }^{92,93}$ Nurses with higher spiritual intelligence are happier in their lives. ${ }^{94}$ Spirituality also significantly improves their job performance including their clinical competence and quality of nursing care. ${ }^{95,96}$ The nurses with higher spiritual well-being had a positive attitude and were able to provide better spiritual care to the patients. ${ }^{97}$ All these evidences very clearly signify the need to enhance the spiritual well-being of the nurses. The organizations are required to understand the spiritual needs of the nurses and should provide opportunities for the nurses to provide spiritually augmented nursing care to their patients.

\subsection{Reporting implications and future research recommendations}

The nurse managers should create a healthy work environment for the nurses by ensuring adequate managerial support for them, providing staff appreciation, providing adequate staffing and resources, providing mutual respect and communication, creating a healthy doctor-nurse interaction, taking nurses' suggestions into consideration, enhancing job autonomy, and teamwork, which will enhance positive emotional experiences, job satisfaction, and enhances overall happiness of nurses. In addition, nurses' salaries and working conditions should be improved, which will definitely improve the nurses' happiness. Therefore, the nurse managers and policymakers should consider the factors that affect the nurses' happiness and plan appropriate interventions to reduce their stress and burnout and enhance their happiness, quality of life, and enthusiasm that improve productivity and delivery of quality nursing care. If such strategies are implemented, the job satisfaction of nurses shall be improved, their retention rates shall be increased, and their shortage can be minimized. Therefore, future interventional studies are required to increase the nurses' happiness, mental health, and health-related quality of life.

\subsection{Limitations of the review}

Our search is restricted to examining the studies that are relevant only to registered nurses working in the hospitals, and the nurse supervisors, nurse managers, nurse educators, and student nurses' happiness were not studied; therefore, the findings of this study cannot be generalized to all the nurse population. Also, the search was restricted to studies published in the English language, and we have excluded 9 similar studies in other languages; therefore, it is possible that additional studies might present different findings. Also, there is a challenge in finding all relevant studies because of very limited studies available on nurses' happiness; however, we have included all the possible studies to the best of our knowledge. The search was also limited to the years from 2010 to 2020; hence, early seminal studies may have been overlooked. We could not conduct a metaanalysis to create a sense of correlation because the option for statistical analysis differed across studies.

\section{Conclusions}

Our review found various organizational and personal predictors that were responsible for nurses' happiness. This data could be used by the hospital administrators and nurse managers to effectively plan strategies to improve the overall happiness of nurses. Nurses' happiness shall be enhanced by reducing job-related stress, improving job satisfaction and mental health, and creating enthusiasm among nurses. This will improve the retention of nurses and reduce the turnover of nurses. 


\section{Authors' contributions}

Dr. Judie Arulappan and Mr. Suthan Pandarakutty conceptualized and designed the study. Mr. Suthan Pandarakutty and Dr. Judie Arulappan conducted the literature review. Dr. Blessy Prabha Valsaraj resolved disagreements between Mr. Suthan Pandarakutty and Dr. Judie Arulappan. Dr. Blessy Prabha Valsaraj was also consulted when the first two authors encountered issues in assessing the study quality. Dr. Judie Arulappan and Mr. Suthan Pandarakutty led the interpretation of findings and drafted the manuscript. Dr. Judie Arulappan

\section{References}

1. Miller CA. Nursing for Wellness in Older Adults: Theory and Practice. 4th edn. Philadelphia, PA: Lippincott Williams \& Wilkins; 2004.

2. Samouei R, Moslehi M, Heydari M, Toghiani Z. Management of students' happiness in dormitories of isfahan university of medical sciences. IJME/ Special issue for educational development and health promotion. 2012;11:1057-1062.

3. Abedi A, Mirzai P. Comparative effectiveness of cognitive - behavioral therapy and social skills training to increase Fordyce happiness of high school students. New Thoughts Educ. 2010;2:59-71.

4. Fisher CD. Happiness at work. Int J Manage Rev. 2010;12:384-412.

5. Ghent A. The happiness effect. Bull World Health Organ, 2011;89:246-247.

6. Rodríguez-Muñoz A, Sanz-Vergel Al. Happiness and well-being at work: a special issue introduction. J Work Organ Psychol. 2013;29:95-97.

7. Broujeni IN, Asadi H. Investigate the relationship between happiness and commitment of the staff of the Ministry of Sport and Iranian Youth. Sport Manage. 2013;6:545-557.

8. Matin H, Jandaghi G, Haghguyan Z. Identification and assessment of the components of happiness at work Components at the implementing agencies in Qom. Public Admin. 2012;1:35-84.

9. Barry SWH. Occupational Health. 4th ed. Lippincott: Wilking Press; 2000.

10. Bagheri F, Akbarizadeh F, Hatami H. The relationship between demographic variables nurses' spiritual intelligence and happiness of Alzahra and Bentolhoda city of Bushehr. Biomedical Research Institute of Persian Gulf 2011. Iran South Med J. 2011;14:256-263.

11. Ozkara San E. Concept analysis of nurses' happiness. Nurs Forum. 2015;50:55-62. and Dr. Blessy Prabha Valsaraj critically reviewed the manuscript for important intellectual content. All authors approved the final manuscript as submitted and agree to be accountable for all aspects of the work.

\section{Ethical approval}

Ethical issues are not involved in this paper.

\section{Conflicts of interest}

All contributing authors declare no conflicts of interest.

12. Badryzadh A, Frhady A, Tarahi MJ, Saki M, Biranovand GR. Evaluation of mental health nurses in public hospitals of Horramabad. J Lorestan Univ Med Sci. 2013;15:62-69.

13. Bahrami A, Akbari $H$, Mousavi S, Hannani M, Ramezani Y. Job stress among the nursing staff of Kashan hospitals. FEYZ. 2011;15:366-373.

14. Duffin C. Only one in seven nurses happy in their job, work survey reveals. Nurs Stand. 2014;28:7, J Lorestan Univ Med Sci. 2014;15:62-69.

15. Azad-Marzabadi E, Tarkhorani H. The relation between job stress and job satisfaction in a group of personnel. J Behav Sci. 2008;1:121-129.

16. Mami S, Mehdian K, Davoodian Z. Investigation of depression rate in nurses working at state hospitals of the city of and its associated factors. J Ilam Univ Med Sci. 2014;22:51-56.

17. Jafary E, Kamarzarin H, Kordmirza E, Sefizadeh V. The role of spiritual well-being and coping skills in prediction of job satisfaction in nurses. $J$ Clin Nurs Midwifery. 2015;4:50-58.

18. Khamse F, Rvhy H, Ebadi A, Hajiamini Z, Suleimi $H$, Radfar Sh. Survey relationship between demographic factors and stress, anxiety and depression in nurses working in selected hospitals in Tehran city. Holist Nurs Midwifery. 2011;21:13-21.

19. Ju EJ, Kwon YC, Nam MH. Influence of clinical nurses work environment and emotional labor on happiness index. J Korean Acad Nurs Admin. 2015;21:212-222.

20. Al-Hawajreh K. Exploring the relationship between occupational stress and organizational commitment among nurses in selected Jordanian hospitals. AnNajah Univ Jr Res. 2011;25:1931-1975.

21. Mealer M, Jones J, Moss M. A qualitative study of resilience and posttraumatic stress disorder in United States ICU nurses. Intensive Care Med. 2012;31:194-203. 
22. Myny D, Van Goubergen D, Gobert M, et al. Nondirect patient care factors influencing nursing workload: a review of the literature. J Adv Nurs. 2011;67:2109-2129.

23. Lin SY, Chiang HY, Chen L. Comparing nurses' intent to leave or stay: Differences of practice environment perceptions. Nurs Health Sci. 2011;13:463-467.

24. Aiken LH, Clarke SP, Sloane DM, Lake ET, Cheney T. Effects of hospital care environment on patient mortality and nurse outcomes. J Nurs Admin. 2008;38:223-229.

25. Kim KN. The effect nursing organizational culture and happiness index on turnover intention among nurses. Korean J Health Serv Management. 2014;8:61-72.

26. American Nurses Association. 2020. https:// www.nursingworld.org/ 4ab39b/globalassets/ practiceandpolicy/2017-year-of-the-healthynurse/2017-yearofthehealthynurse-factsheet.pdf. Accessed September 15, 2020.

27. Liberati A, Altman DG, Tetzlaff J, et al. The PRISMA statement for reporting systematic reviews and meta-analyses of studies that evaluate healthcare interventions: explanation and elaboration. BMJ. 2009;339:b2700.

28. Gurdogan E, Uslusoy E. The relationship between quality of work life and happiness in nurses: A sample from Turkey. Int J Caring Sci. 2020;12:1364-1371.

29. Duche Pérez A, Rivera Galdos, G. Job satisfaction and happiness in Peruvian nurses. Enfermería Global. 2019;18:353-373.

30. Hwang E. Effects of the organizational culture type, job satisfaction, and job stress on nurses' happiness: a cross-sectional study of the long-term care hospitals of South Korea. Jpn J Nurs Sci. 2018;16:263-273.

31. Deluga A, Dobrowolska B, Kosicka B, Ślusarska B, Jędrych M, Brzozowska A. The significance of health in the hierarchy of personal values among nurses. Med Stud. 2018;34:64-69.

32. Yahya Alhakami I, Ghazi Baker O. Nurses' happiness and awareness of their influence on work in governmental and private hospitals. Clin Nurs Stud. 2018;7:21.

33. Khosrojerdi Z, Tagharrobi Z, Sooki Z, Sharifi K. Predictors of happiness among Iranian nurses. Int $J$ Nurs Sci. 2018;5:281-286.

34. Farahnaz F, Fateme Rahighee Y, Maryam Salehzadeh A. Effect of life skills education on nurses' happiness. Am J Exp Clin Res. 2016;3:157-160.
35. Meng R, Luo Y, Liu B, Hu Y, Yu C. The nurses' well-being index and factors influencing this index among nurses in central China: a cross-sectional study. PLoS One 2015;10:e0144414.

36. Abdollahi A, Abu Talib M, Yaacob S, Ismail Z. Hardiness as a mediator between perceived stress and happiness in nurses. J Psychiatr Ment Health Nurs. 2014;21:789-796.

37. Mirfarhadi N, Moosavi S, Tabari R. Life satisfaction and its determinants: a survey on Iranian nurse's population. Adv Biosci. 2013;4:11-15.

38. Appel L, Labhart L, Balczo P, McCleary N, Raley $M$, Winsstt R. A comparative study of a happiness intervention in medical-surgical nurses. Medsurg Nurs. 2013;22:319-324.

39. Einarsdóttir J. Happiness in the neonatal intensive care unit: merits of ethnographic fieldwork. Int $J$ Qual Stud Health Well-Being. 2012;7:19699.

40. Habib S, Riaz M, Akram M. Emotional intelligence as predictor of life satisfaction among nurses: mediating role of spiritual wellness. FWU J Soc Sci. 2012;6:73-78.

41. Wells GA, Shea B, O'Connell D, et al. The Newcastle-Ottawa Scale (NOS) for assessing the quality if nonrandomized studies in meta-analyses. 2009. http://www.ohri.ca/programs/clinical_epidemiology/ oxford.htm. Accessed September 15, 2020.

42. Pluye RE, Cargo M, Barlett G, et al. Proposal: A Mixed Methods Appraisal Tool for Systematic Mixed Studies Reviews. Montreal, Canada: Department of Family Medicine, McGill University; 2011.

43. Jun W, Jo M. Factor affecting happiness among nursing students in South Korea. J Psychiatr Ment Health Nurs. 2016;23:419-426.

44. Moghadam A. The relation between happiness and life expectancy among the nurses in Tehran. J Soc Issues Humanit. 2014;2:367-369.

45. Kose BG, Balik T, Kurt S, Ozturk H. Happiness levels of the nurses working at a University Hospital. New Trends Issues Proc Adv Pure Appl Sci. 2018;10:62-68.

46. Golparvar M, Abedini H. The Relationship between spirituality and meaning at work and the job happiness and psychological well-being: a spiritualaffective approach to the psychological well-being. Int J Manage Sustainability Conscientia Beam. 2014;3:160-175.

47. Yosefi M. Comparison of happiness, psychology well-being and job perfectionism among women nurses of different sections of hospitals in Isfahan at 2014. Sci J Hamadan Nurs Midwifery Fac. 2015;23:52-62. 
48. Rahighee F. A descriptive study of nurses' happiness at Shahid Sadoughi Hospital, Iran. J Mental Disord Treat. 2015;1:102.

49. Ramesh N, Nisha C, Josephine AM, Thomas S, Joseph B. A study on quality of work life among nurses in a medical college hospital in Bangalore. Natl J Commun Med. 2013;4:471-474.

50. Sedoughi Z, Sadeghi M, Shahraki SK, Anari SHS, Amiresmaili $M$. The relation of work, family, and life quality of nurses working at teaching hospitals of Kerman-Iran. Bali Med J. 2016;5:110-115.

51. Dai H, Tang F, Chen IJ, Yu S. Taiwanese version of the work-related quality of life scale for nurses: translation and validation. J Nurs Res. 2016;24:58-67.

52. Cam O, Yildirim S. Job satisfaction in nurses and effective factors: review. Turkiye Klinikleri J Nurs Sci. 2010;2:64-70.

53. Epp K. Burnout in critical care nurses: a literature review. Dynamics. 2012;23:25-31.

54. Mohamed FA, Gaafar YA, Abd Alkader WM. Pediatric nurses' stresses in intensive care units and its related factors. J Am Sci. 2011;7:304-315.

55. Nouroozi Kushali A, Hajiamini Z, Ebadi A, Khamseh F, Rafieyan Z, Sadeghi A. Comparison of intensive care unit and general wards nurses' emotional reactions and health status. J Shahid Beheshti Sch Nurs Midwifery. 2012;80:15-23.

56. Vahedian-Azimi A, Hajiesmaeili M, Kangasniemi M, et al. Effects of stress on critical care nurses: a national cross-sectional study. J Inten Care Med. 2017;34:311-322.

57. Al Sinawi H, Al Toubi A, Al-Nabhani A. Burnout, perceived stress and coping styles among nurses at a tertiary care hospital in Muscat. Arab J Psychiatry, 2016;27:117-126.

58. Ghanbary A, Bqayy M. Nursing research priorities in the care of patients with cancer of the nurse's view. Iran J Nurs. 2010;57:87-97.

59. Ozturk R, Gulec D, Guneri SE, Sevil U, Gurmen $\mathrm{N}$. Investigation of the relationship between patient satisfaction with quality of nursing work life. Balıkesir Health Sci J. 2013;2:167-174.

60. Toode K, Routasalo P, Helminen M, et al. Hospital nurses' individual priorities, internal psychological states and work motivation. Int Nurs Rev Int Counc Nurses. 2014;61:361-370.

61. Warr P. Jobs, and job-holders: two sources of happiness and unhappiness. In: David SA, Boniwell I, Ayers AC, eds. The Oxford Handbook of Happiness. Oxford, UK: Oxford University Press; 2013:733-750.

62. Blumberga S, Olava S. Quality of hospital nursing work life, psychological and subjective well-being. Rural Environ Educ Pers. 2016;13:295-300.
63. Mudallal RH, Saleh M, Al-Modallal HM, et al. Quality of nursing care: The influence of work conditions, nurse characteristics and burnout. Int J Afr Nurs Sci. 2017;7:24-30.

64. Spence Laschinger HK, Nosko A, Wilk P, Finegan J. Effects of unit empowerment and perceived support for professional nursing practice on unit effectiveness and individual nurse well-being: a timelagged study. Int J Nurs Stud. 2014;51:1615-1623.

65. Mousavi S, Amini K, Ramezani-Badr F, Roohani M. Correlation of happiness and professional autonomy in Iranian nurses. J Res Nurs. 2019;24:622-632.

66. Buaklee P, Fongkaew W, Turale S, Akkadechanunt T, Sansiriphun N. Unveiling the experiences of happiness at work through narrative inquiry: advanced practice nurses' perspectives. Pacific Rim Int J Nurs Res. 2017;21:206-219.

67. Yiengprugsawan V, Somboonsook B. Seubsman S-A, Sleigh AC. Happiness, mental health, and socio-demographic associations among a national cohort of Thai adults. J Happiness Stud. 2012;13:1019-1029.

68. Chan C, Wong H, Yip P. Associations of relative income deprivation with perceived happiness and self-rated health among the Hong Kong Chinese population. Int J Publ Health. 2017;62:697-707.

69. Kousar S, Hussain M, Afzal M, Amir D, Gilani SA, Azhar MR. Impact of job satisfaction on nurses' performance. Saudi J Nurs Health Care. 2018;1:49-55.

70. Kahneman D, Deaton A. High income improves evaluation of life but not emotional well-being. Proc Natl Acad Sci USA. 2010;107:16489-16493.

71. Gavin JH, Mason RO. The virtuous organization: The value of happiness in the workplace. Organ Dyn. 2004;33:379-392.

72. Abbott D, De La Garza M, Krantz S, Mahvi D. The impact of physician-nurse interactions on nurse satisfaction. J Surg Res. 2011;165:203.

73. Jouybari L, Sharifi AN, Sanagoo A, Saeedi S, Saeedi S, Kalantari S. Happiness and its related factors among students in Golestan university of medical sciences. J Nurs Educ. 2017;5:40-45.

74. Javanmardnejad S, Heravi-Karimooi M, Rejeh N, $\mathrm{Nia}$ HS. Happiness in nurses working in the emergency department of the hospitals of llam University of Medical Sciences in 2019. J Crit Care Nurs. 2018;11:1-8 (in Iranian).

75. Sparksks S, Corcoran KJ, Nabors LA, Hovanitz CA. Job satisfaction and subjective well-being in a sample of nurses. J App/ Soc Psychol. 2005;35:922-938.

76. Siamian H, Naeimi OB, Shahrabi A, et al. The status of happiness and its association with demographic variables among the paramedical students. J Mazandaran Univ Med Sci 2012;21:159-166. 
77. Nave Leal E, Pais-Ribeiro JL, Oliveira M. Happiness, hope, and affection as predictors of quality of life and functionality of individuals with heart failure at three-month follow-up. Psychol Res. 2012;2:532-539.

78. Sarang SD, Shitole RB, Karnam AG. To investigate the association between sleep and happiness among nurses with different personality traits: a cross-sectional study. Indian J Occup Ther [serial online]. 2019;51:3-7. Accessed August 22, 2020.

79. Liu R, Zeng P, Quan P. The role of hope and selfefficacy on nurses' subjective well-being. Asian Soc Sci. 2018;14:18-22.

80. Bourgault P, Lavoie S, Paul-Savoie E, et al. Relationship between empathy and well-being among emergency nurses. J Emergency Nurs. 2015;41:323-328.

81. Mahdavi Haji T, Mohammadkhani S, Hahtami M. The effectiveness of life skills training on happiness, quality of life and emotion regulation. Procedia-Soc Behav Sci. 2011;30:407-411.

82. Javadi M, Sepahvand MJ, Mahmudi H, Sori A. The effect of life skills training on quality of life in nurses of Khorramabad Hospitals. Sci J Hamadan Nurs Midwifery Fac. 2013;21:32-40.

83. Delahaij R, Gaillard AWK, van Dam K. Hardiness and the response to stressful situations: investigating mediating processes. Per Individ Dif. 2010;49:386-390.

84. Seo E, Kim S, Kim S, Kim J, Park J, Yoon H. Life satisfaction and happiness associated with depressive symptoms among university students: a crosssectional study in Korea. Ann Gen Psychiatry. 2018;17:52.

85. Maharaj S, Lees T, Lal S. Prevalence and risk factors of depression, anxiety, and stress in a cohort of Australian nurses. Int J Environ Res Public Health. 2018;16:61.

86. Oates J, Jones J, Drey N. Subjective well-being of mental health nurses in the United Kingdom: results of an online survey. Int $J$ Mental Health Nurs. 2017;26:391-401.
87. Al-Dubai SA, Rampal KG. Prevalence and associated factors of burnout among doctors in Yemen. J Occup Health. 2010;52:58-65.

88. Lee H, Song R, Cho YS, Lee GZ, Daly B. A comprehensive model for predicting burnout in Korean nurses. J Adv Nurs. 2003;44:534-545.

89. Lewicka M, Dzierżak A, Sulima M. Health as a value in the opinion of students of nursing and midwifery. J Public Health Nurs Med Rescue. 2013;4:22-28.

90. Stutzer A, Frey BS. Does marriage make people happy, or do happy people get married? J SocioEcon. 2006;35:326-347.

91. Schiffrin HH, Nelson SK. Stressed and happy? Investigating the relationship between happiness and perceived stress. J Happiness Stud. 2010;11:3339.

92. Ebadi B, Hosseini M, Rahgoi A, Fallahi Khoshknab $M$, Biglarian A. The relationship between spiritual health and happiness among nursing students. J Nurs Educ. 2016;5:23-30.

93. Sahebalzamani M, Farahani H, Abasi R, Talebi $M$. The relationship between spiritual intelligence with psychological well-being and purpose in life of nurses. Iran J Nurs Midwifery Res. 2013;18:38-41.

94. Faribors B, Fatemeh A, Hamidreza $H$. The relationship between nurses' spiritual intelligence and happiness in Iran. Procedia Soc Behav Sci. 2010;5:1556-1561.

95. Khandan M, Eyni Z, Koohpaei A. Relationship between spiritual intelligence and job performance: a case study of nurses and nursing aids in the main University Hospital of Qom, Iran. Health Spiritual Med Ethics. 2017;4:8.

96. Karimi-Moonaghi $H$, Gazerani A, Vaghee S, Gholami H, Salehmoghaddam A, Gharibnavaz R. Relation between spiritual intelligence and clinical competency of nurses in Iran. Iran J Nurs Midwifery Res. 2015;20:665.

97. Azarsa T, Davoodi A, Khorami Markani A, Gahramanian A, Vargaeei A. Spiritual wellbeing, attitude toward spiritual care and its relationship with spiritual care competence among critical care nurses. J Caring Sci. 2015;4:309-320. 